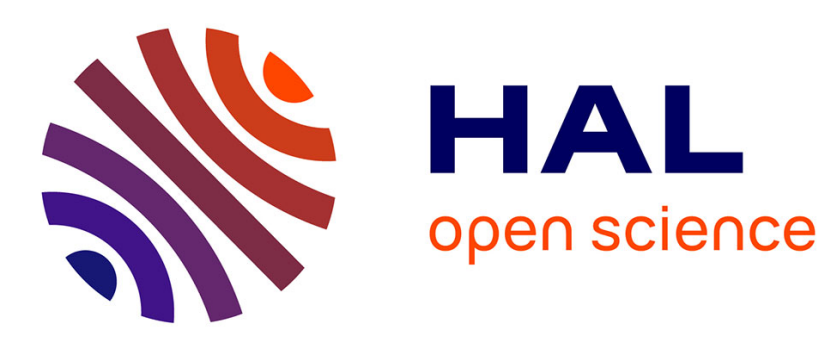

\title{
Optical properties of Ag-Cu alloys : evidence for d-virtual bound states on $\mathrm{Cu}$ impurities
}

\author{
J. Rivory, M.L. Theye
}

\section{To cite this version:}

J. Rivory, M.L. Theye. Optical properties of $\mathrm{Ag}-\mathrm{Cu}$ alloys: evidence for d-virtual bound states on $\mathrm{Cu}$ impurities. Journal de Physique Lettres, 1975, 36 (5), pp.129-132. 10.1051/jphyslet:01975003605012900 . jpa-00231170

\section{HAL Id: jpa-00231170 https://hal.science/jpa-00231170}

Submitted on 1 Jan 1975

HAL is a multi-disciplinary open access archive for the deposit and dissemination of scientific research documents, whether they are published or not. The documents may come from teaching and research institutions in France or abroad, or from public or private research centers.
L'archive ouverte pluridisciplinaire HAL, est destinée au dépôt et à la diffusion de documents scientifiques de niveau recherche, publiés ou non, émanant des établissements d'enseignement et de recherche français ou étrangers, des laboratoires publics ou privés. 


\title{
OPTICAL PROPERTIES OF Ag-Cu ALLOYS : EVIDENCE FOR d-VIRTUAL BOUND STATES ON Cu IMPURITIES (*)
}

\author{
J. RIVORY and M. L. THEYE \\ Laboratoire d'Optique des Solides $\left({ }^{* *}\right)$, Université Paris VI, \\ 75230 Paris, Cedex 05, France
}

(Reçu le 13 janvier 1975, accepté le 27 février 1975)

\begin{abstract}
Résumé. - Les propriétés optiques de solutions solides métastables $\mathrm{Ag}-\mathrm{Cu}$ en toutes concentrations ont été déterminées et analysées entre 0,5 et $6 \mathrm{eV}$; les résultats relatifs aux alliages riches en $\mathrm{Ag}$ sont interprétés en termes du modèle des niveaux liés virtuels.
\end{abstract}

\begin{abstract}
The optical properties of metastable Ag-Cu solid solutions over the whole composition range have been determined and analyzed between 0.5 and $6 \mathrm{eV}$; the results relative to $\mathrm{Ag}$ rich alloys are interpreted in terms of the virtual bound state model.
\end{abstract}

The theory of the electronic structure of substitutionally disordered alloys, especially those which contain localized electronic states such as d-states, has been developed considerably in recent years [1-5]. The theoretical models still need to be tested against experimental results for representative alloys. $\mathrm{Ag}-\mathrm{Cu}$ alloys are particularly interesting in this respect because of the small overlap of the d-bands of the pure constituents. As a result of experimental difficulties, they have been little investigated : in addition to differential measurements on very dilute alloys [6], only two studies, by optical absorption [7] and by high-energy photoemission [8] have been reported for concentrated alloys. We present the results of an optical investigation of $\mathrm{Ag}$-Cu alloys over the whole concentration range and we interpret them according to the virtual bound state theory $[1,2]$.

As the solubility of $\mathrm{Ag}$ and $\mathrm{Cu}$ in each other is very small [9], only metastable solid solutions can exist in the non-dilute range. We tried to prepare such samples over the whole composition range in the form of thin films deposited by simultaneous evaporation of the two metals from the same tungsten crucible onto silica substrates, under a classical vacuum of $10^{-7}$ torr. The film structure and homogeneity were controlled by electron microscopy and electron diffraction performed on pieces of the same films stripped off the substrate. The film thickness (ranging from 100 to $400 \AA$ ) was determined by $\mathrm{X}$-ray interferences with $1 \%$ accuracy [10] and the

$\left.{ }^{*}\right)$ The research reported herein has been sponsored in part by the U.S. Department of the Army, through its European Research Office.

$\left({ }^{* *}\right)$ Equipe de Recherche associée au C.N.R.S. alloy composition by electron microprobe analysis with $1 \%$ accuracy [11]. Homogeneous films could only be obtained by using very high deposition rates (flash evaporation) and by depositing the films on substrates held at low temperatures $(\sim 180 \mathrm{~K})$; introduction of $\mathrm{Ar}$ in the vacuum chamber while the film was maintained at low temperature seemed to prevent atomic rearrangements leading to phaseseparation when bringing the samples back to room temperature for optical studies. These films consisted of very small crystallites of about 15-20 $\AA$ (i.e. 3 or 4 atomic cells); truly amorphous films were obtained only when deposited at temperatures lower than $60 \mathrm{~K}$. The diffraction diagrams, although very broad, were representative of real solid solutions. Annealing produced both recrystallization and phase-separation.

The complex dielectric constant $\widetilde{\varepsilon}$ was determined between 0.5 and $6 \mathrm{eV}$ from the film reflectance and transmittance measured in air at room temperature, the film thickness being known [12]; this method was supplemented in some cases by a KramersKronig analysis of the reflectance data [13].

Figure 1 shows the imaginary part $\varepsilon_{2}$ of the dielectric constant versus energy between 2 and $6 \mathrm{eV}$, for a number of $\mathrm{Ag}-\mathrm{Cu}$ alloys as well as for pure $\mathrm{Ag}$ and pure $\mathrm{Cu}$. The modification of the $\varepsilon_{2}$ spectrum when going from $\mathrm{Cu}$ to $\mathrm{Ag}$ by alloying is strikingly different from what is observed for $\mathrm{Ag}-\mathrm{Au}$ and $\mathrm{Cu}-\mathrm{Au}$ alloys $[14,15,16]$. In these cases, the absorption edge moves continuously (although not linearly) and changes its shape smoothly from the edge of one pure constituent to the other, which is interpreted as being due to the shift and deformation of a common d-band. For the Ag-Cu alloys, there is no continuous modification of the spectrum and one must consider 


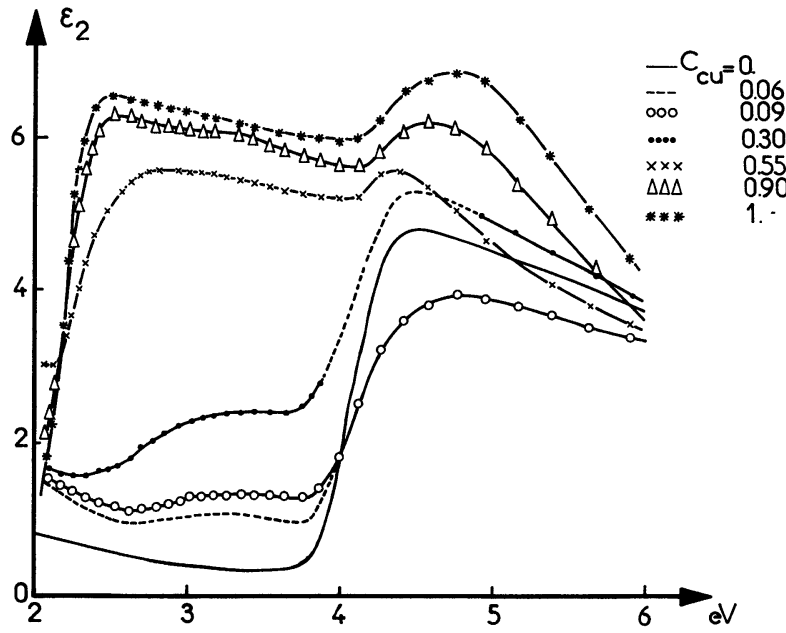

FIG. 1. - Imaginary part $\varepsilon_{2}$ of the dielectric constant versus energy for $\mathrm{Ag}-\mathrm{Cu}$ alloys with different $\mathrm{Cu}$ concentrations, and for pure $\mathrm{Ag}$ and pure $\mathrm{Cu}$.

separately the $\mathrm{Cu}$-rich alloys, for which $\varepsilon_{2}$ is roughly $\mathrm{Cu}$-like, and the Ag-rich alloys which present an original behavior to be discussed later.

For $\mathrm{Cu}$-rich alloys, the $\varepsilon_{2}$ spectrum stays very similar to the pure $\mathrm{Cu}$ spectrum (up to $c_{\mathrm{Cu}}=0.55$ ). For small $\mathrm{Ag}$ concentrations, the absorption edge is very steep and located at the same energy as in pure $\mathrm{Cu}: 2.15 \mathrm{eV}$. When $c_{\mathrm{Ag}}$ increases, it is broadened but not shifted; the first maximum is rounded and shifted to higher energies (broadening effects may simply be due to disorder in these microcrystalline samples). Since the absorption edge in pure $\mathrm{Cu}$, as for other noble metals, is mainly determined by transitions from the top of the d-band to the conduction band at the Fermi level, the upper part of the $\mathrm{Cu}$ partial d-band must be little affected by alloying with Ag. The second edge starting at $4 \mathrm{eV}$ in pure $\mathrm{Cu}$ can still be seen at the same energy in the alloys, while the maximum centered at $4.8 \mathrm{eV}$ decreases in intensity, becomes narrower and moves to lower energies. It is difficult to separate out the different contributions in this spectral range; the modification of the $\varepsilon_{2}$ curve around $5 \mathrm{eV}$ is tentatively attributed to a perturbation of the bottom of the partial $\mathrm{Cu}$ d-band, due possibly to the presence of $\mathrm{Ag}$ d-states.

For Ag-rich alloys, the $\varepsilon_{2}$ spectrum shows two distinct parts : a high-energy portion which is very similar to the interband absorption in pure $\mathrm{Ag}$, and a low-energy part which must represent the $\mathrm{Cu}$ impurity contribution. The absorption edge looks very much like the pure Ag edge, except for broadening effects; it has the same energy dependence and leads by extrapolation to the same onset for interband transitions from the top of the Ag partial d-band to the Fermi level : $3.85 \mathrm{eV}$. The upper part of that band is therefore not affected by alloying with $\mathrm{Cu}$.

Between 2 and $4 \mathrm{eV}$, the impurity contribution shows up as a bump superimposed on the matrix intraband contribution to $\varepsilon_{2}$; its intensity increases with $\mathrm{Cu}$ concentration while it remains centered at about $3.2 \mathrm{eV}$ (even up to $c_{\mathrm{Cu}}=0.30$ ). This behavior is completely original in the noble metal alloys series but it looks very similar to the contribution of transition impurities in $\mathrm{Ag}$, for example in Ag-Pd alloys [18, 19]. It may be inferred that, in $\mathrm{Ag}-\mathrm{Cu}$ alloys, the $\mathrm{Cu}$ d-levels are in resonance with the continuum of conduction states and form virtual bound states localized on the $\mathrm{Cu}$ atoms, clearly distinct from the unperturbed d-band of the Ag matrix.

Theoretical expressions for the frequency-dependent optical absorption due to virtual bound state impurities have been derived by Caroli [20] and by Kjollerstrom [21]. We shall follow here the more intuitive treatment proposed by Beaglehole [22]. Absorption due to the presence of impurities takes place by two processes : resonant scattering of conduction electrons by the impurity d-states and excitation of impurity d-electrons to empty conduction states (and of host electrons to empty impurity states). The first process is accounted for by a generalized Drude formule :

$$
\varepsilon_{2 \mathrm{c}}=\frac{\omega_{\mathrm{p}}^{2}}{\omega \tau_{\mathrm{a}}\left(\omega^{2} \cdot+\tau_{\mathrm{a}}^{-2}\right)}
$$

where $\omega_{p}$ is the plasma frequency of the matrix and $\tau_{\mathrm{a}}$, the relaxation time in the alloy, is given by :

$$
\frac{1}{\tau_{\mathrm{a}}}=\frac{1}{\tau_{\mathrm{p}}}+\frac{c}{\tau_{\mathrm{i}}}
$$

$\tau_{\mathrm{p}}$ is the relaxation time of the pure matrix (related to phonons, defects and other impurities) and $\tau_{\mathrm{i}}$ the frequency dependent relaxation time due to scattering by the impurity with concentration $c$. If $E_{\mathrm{d}}$ and $\Delta$ are respectively the position with respect to the Fermi level and the half-width of the virtual bound state density, assumed to be Lorentzian, then $\tau_{\mathbf{i}}$ is given by :

$$
\begin{aligned}
\frac{1}{\tau_{\mathrm{i}}}=\frac{1}{\tau_{\mathrm{i}}(0)} & \frac{E_{\mathrm{d}}^{2}+\Delta^{2}}{2 \omega \Delta} \times \\
\times & {\left[\tan ^{-1}\left(\frac{\omega+E_{\mathrm{d}}}{\Delta}\right)+\tan ^{-1}\left(\frac{\omega-E_{\mathrm{d}}}{\Delta}\right)\right] . }
\end{aligned}
$$

The second process (interband transitions) gives a contribution :

$$
\begin{aligned}
\varepsilon_{2 B}=c\left(\frac{\omega_{\mathrm{d}}}{\omega}\right)^{2} \times \\
\times\left[\tan ^{-1}\left(\frac{\omega+E_{\mathrm{d}}}{\Delta}\right)+\tan ^{-1}\left(\frac{\omega-E_{\mathrm{d}}}{\Delta}\right)\right]
\end{aligned}
$$

where $\omega_{d}$ is proportional to the matrix element characterizing these transitions (assumed to be cons$\tan t)$.

In this model, the experimental $\varepsilon_{2}$ data below the onset of $\mathrm{Ag}$ interband transitions (i.e. between 0.5 
and $3.5 \mathrm{eV}$ ) must be described by the expression :

$$
\varepsilon_{2}=\varepsilon_{2 \mathrm{c}}+\varepsilon_{2 B},
$$

which allows one to determine by a least square method the four parameters characterizing the $\mathrm{Cu}$ $\mathrm{d}$-virtual bound states in $\mathrm{Ag}: E_{\mathrm{d}}, \Delta, \omega_{\mathrm{d}}$ and $\tau_{\mathrm{i}}(0)$. The parameters $\tau_{\mathrm{p}}$ and $\omega_{\mathrm{p}}$, which correspond to the pure matrix, are difficult to choose : $\tau_{\mathrm{p}}$ is strongly dependent on sample structure $\left(\hbar / \tau_{\mathrm{p}}\right.$ may vary from 0.025 to $0.05 \mathrm{eV}$ for pure $\mathrm{Ag}$ films) and there remains some theoretical ambiguity concerning the value of $\omega_{\mathrm{p}}$ in such treatments [23]. It was possible to determine simultaneously five parameters : $E_{\mathrm{d}}, \Delta$, $\omega_{\mathrm{d}}, \tau_{\mathrm{i}}(0)$ and $\omega_{\mathrm{p}}, \tau_{\mathrm{p}}^{-1}$ being fixed at different physically reasonable values; the results (especially the values of $E_{\mathrm{d}}$ and $\Delta$ ) were not very sensitive to the choice of $\tau_{\mathbf{p}}$. The fitting was performed on the quantity $\omega \varepsilon_{2}$, which gave more weight to the high energy values of $\varepsilon_{2}$. Figure 2 shows these results for two
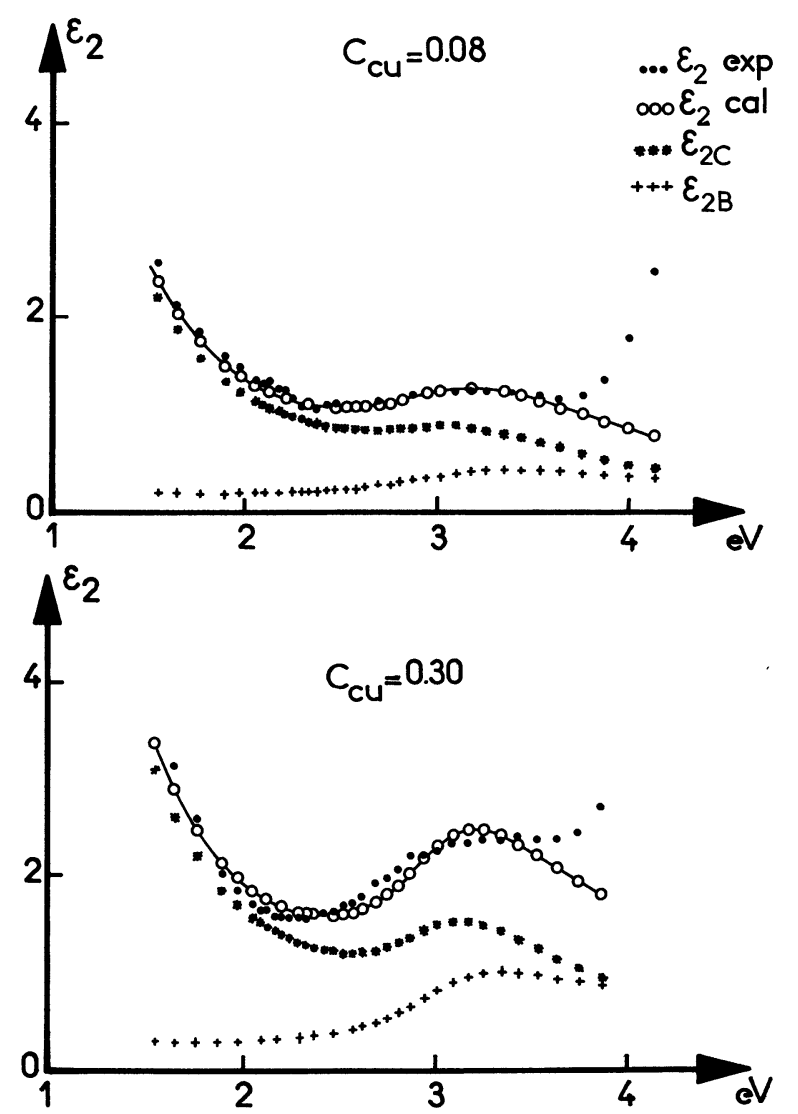

FIG. 2. - Results of the fitting procedure in the virtual bound state model for Ag-rich alloys, showing the experimental (..) and the calculated $(\circ) \varepsilon_{2}$ curves, as well as the theoretical intraband $(*)$ and interband $(++)$ contributions to $\varepsilon_{2}$. alloys with $\mathrm{Cu}$ concentrations 0.08 and 0.30 ; the two partial contributions $\varepsilon_{2 \mathrm{c}}$ and $\varepsilon_{2 B}$ are indicated. The fitting is quite good for the dilute alloy, less good for the more concentrated one in which interactions of impurity atoms must already be large; however, the values of the parameters were the same in both cases. The main parameters $E_{\mathrm{d}}$ and $\Delta$ are determined with a few $\%$ accuracy, $\omega_{\mathrm{d}}$ less accurately; $\tau_{\mathrm{i}}(0)$ and $\omega_{\mathrm{p}}$ were often strongly correlated, and their values are more scattered. Table I gives the values of $E_{\mathrm{d}}, \Delta$ and $\omega_{\mathrm{d}}$ for a few alloys, including the more concentrated one : the d-virtual bound states localized on $\mathrm{Cu}$ impurities in a $\mathrm{Ag}$ matrix are located at about $3.1 \mathrm{eV}$ below the Fermi level and have a half-width of about $0.45 \mathrm{eV}$; the matrix element parameter for interband d-s transitions $\omega_{\mathrm{d}}$ is about $4 \mathrm{eV}$.

\section{TABLE I}

Position with respect to the Fermi level $E_{\mathrm{d}}$ and half-width $\mathrm{\Delta}$ of $\mathrm{Cu}$ d-virtual bound states in $\mathrm{Ag}$, and coupling parameter for d-s transition $\omega_{\mathrm{d}}$ deduced from the optical absorption as explained in the text for different Ag-rich alloys.

Cu concentration
-
0.06
0.08
0.09
0.10
0.30

$$
\begin{array}{rcc}
E_{\mathrm{d}}(\mathrm{eV}) & \Delta(\mathrm{eV}) & \omega_{\mathrm{d}}(\mathrm{eV}) \\
- & - & - \\
3.1 \pm 0.1 & 0.56 \pm 0.06 & 4.4 \\
3.0 \pm 0.1 & 0.4 \pm 0.1 & \\
3.15 \pm 0.1 & 0.45 \pm 0.1 & 3.6-4.0 \\
3.1 \pm 0.1 & 0.5 \pm 0.1 & 4-5 \\
3 \pm 0.1 & 0.31 \pm 0.05 & 3-4
\end{array}
$$

In conclusion, we have succeeded in preparing true Ag-Cu solid solutions over the whole composition range by vacuum deposition on substrates at low temperature and we have measured and analyzed their optical properties. The optical absorption of $\mathrm{Cu}$-rich alloys remain very similar to that of pure $\mathrm{Cu}$, except for broadening effects at the edge and for changes at higher energies, probably related to the presence of the $\mathrm{Ag}$ partial d-state density in the vicinity of the bottom of the $\mathrm{Cu}$ partial d-band. In Ag-rich alloys, that part of the absorption spectrum due to the partial $\mathrm{Ag}$ d-band remains unchanged and the additional structure attributed to the $\mathrm{Cu}$ impurities can be interpreted in terms of the virtual bound state model. The observed non-modification of the upper part of the matrix d-band in the dilute cases, as well as the position and width of the d-virtual bound states on $\mathrm{Cu}$ impurities in $\mathrm{Ag}$ deduced from our data agree remarkably well with the results of high-energy photoemission experiments [9].

\section{References}

[1] Friedel, J., Can. J. Phys. 34 (1956) 1190; Suppl. Nuovo Cimento 7 (1958) 287.

[2] Anderson, P. W., Phys. Rev. 124 (1961) 41.

[3] Soven, P., Phys. Rev. 156 (1957) 809; Phys. Rev. 178 (1969) 1136.
[4] Velicky, B., Kirkpatrick, S. and Ehrenreich, H., Phys. Rev. 175 (1968) 747.

[5] Schwartz, L. M., Brouers, F., Vedyayev, A. V. and EhrenREICH, H., Phys. Rev. B 4 (1971) 3383.

[6] Beaglehole, D., Erlbach, E., Phys. Rev. B 6 (1972) 1209. 
[7] Nilsson, P. O. and Forssell, G., J. Physique Colloq. 35 (1974) C4-57.

[8] Shevchik, N. J. and Goldmann, A., to be published in Proceedings of the Electron Spectroscopy Conference, Namur (1974).

[9] Hansen, M., in Constitution of Binary Alloys (McGraw Hill, New York) 1958 p. 18

[10] Umrath, W., Z. Angew. Phys. 22 (1967) 406.

[11] Philibert, J., Rivory, J., Bryckaert, D. and Tixier, R., J. Phys. D 3 (1970) L-70.

[12] Abeles, F. and TheYe, M. L., Surf. Sci. 5 (1966) 325.

[13] Rivory, J., to be published.

[14] Nilsson, P. O., Phys. Kond. Mater. 11 (1970) 1.
[15] Rivory, J., 3rd cycle thesis, Paris (1970), unpublished.

[16] Rivory, J., J. Physique Colloq. 35 (1974) C4-51.

[17] Dujardin, M. M. and Theye, M. L., J. Phys. Chem. Solids 32 (1971) 2033.

[18] Myers, H., Wallden, L. and Karlsson, A., Phil. Mag. 18 (1968) 725.

[19] Callender, A. B. and Schnatterly, S. E., Phys. Rev. B 7 (1973) 4385.

[20] Caroli, B., Phys. Kond. Mater. 1 (1963) 346.

[21] Kuollerstrom, B., Phil. Mag. 19 (1969) 1207.

[22] Beaglehole, D., Phys. Lett. 40A (1972) 209.

[23] Beaglehole, D., to be published. 